\title{
Efecto de la temperatura en la transformación de promastigotes en amastigotes de Leishmania amazonensis in vitro
}

\author{
María Clara Echeverry ${ }^{1}$, Enrique Winograd ${ }^{2}$
}

\begin{abstract}
Resumen
Aunque el efecto de la temperatura en la transformación axénica de Leishmania ha sido ampliamente estudiado, el papel que esta variable juega en la transformación del parásito intracelular se desconoce. El objetivo del presente trabajo fue evaluar si la transformación intracelular de promastigotes en amastigotes ocurre a bajas temperaturas. Cuando se infectaron macrófagos murinos de la línea celular J-774 a dos temperaturas diferentes (24 y $33^{\circ} \mathrm{C}$ ), se observaron formas intracelulares de Leishmania amazonensis a las dos temperaturas. Los parásitos intracelulares producidos se compararon mediante criterios morfológicos, inmunológicos y ultraestructurales. Los resultados indican que los parásitos obtenidos en infecciones a $33^{\circ} \mathrm{C}$ son similares morfológica, inmunológica y ultraestructuralmente con las formas intracelulares obtenidas in vivo conocidas como amastigotes; sin embargo, los parásitos producidos a temperaturas más bajas $\left(24^{\circ} \mathrm{C}\right)$ no tienen similitud antigénica ni ultraestructural con los anteriores. Se concluye que la temperatura cumple un papel relevante en la transformación de la forma extracelular de Leishmania amazonensis hacia la forma intracelular durante su invasión a macrófagos murinos.
\end{abstract}

\section{Summary}

Although it is well known that the effect of temperature is important in the transformation of Leishmania promastigotes into amastigotes under axenic conditions, the contribution of this variable in the transformation of intracellular parasites is presently unknown. When $\mathrm{J}-774$ murine cell line macrophages were infected with Leishmania amazonensis at two different temperatures $\left(24\right.$ and $\left.33^{\circ} \mathrm{C}\right)$, intracellular parasites were observed at both temperatures. The resulting intracellular parasites were compared by morphological, immunological and structural criteria. The results indicate that while parasites produced at $33^{\circ} \mathrm{C}$ have characteristics similar to those previoulsy reported in the literature, infection of macrophages at lower temperatures resulted in intracellular parasites with no evidence of transformation into amastigotes. These results indicate that temperature is essential for the intracellular transformation of promastigotes into amastigotes.

Los microorganismos agrupados en el género Leishmania requieren un hospedero invertebrado -flebotomíneos del género Lutzomia- y uno vertebrado para completar su ciclo de vida. Leishmaniase presenta como una célula flagelada extracelular (promastigote) que habita el intestino del insecto y mediante su picadura a un vertebrado penetra en su torrente sanguíneo, teniendo como blanco las células fagocíticas del tipo macrófago. Al interactuar con estas células, se hace intra-

Laboratorio de Biología Celular, Instituto Nacional de Salud, Santa Fe de Bogotá.

2 Departamento de Química, Universidad Nacional de Colombia, Santa Fe de Bogotá. 
celular y es incluido en un compartimento ácido, $\mathrm{pH} 4,75-5,50(1,2)$, conocido como vacuola parasitófora, dentro de la cual se transforma en una célula aflagelada, redondeada, de menores dimensiones que el promastigote, que se conoce como amastigote. Los amastigotes se reproducen y están en capacidad de invadir nuevas células hospederas.

Varios estudios sobre transformación axénica han explorado independientemente variables como el aumento en la temperatura (7-10) y la disminución del $\mathrm{pH}(11)$ y el efecto sumado de estas dos (1216) en la diferenciación del promastigote en amastigote. El consenso que se desprende de estos ensayos afirma la importancia de estas dos variables en el proceso de transformación $(13,19)$.

El cambio de promastigote en amastigote in vitro también se produce cuando promastigotes de Leishmania se ponen en contacto con cultivos primarios o líneas celulares de macrófagos, a temperaturas de 34 a $37^{\circ} \mathrm{C}$, dependiendo de la especie de Leishmania (17-18). Los parásitos intracelulares producidos de esta manera presentan características antigénicas, morfológicas y ultraestruturales similares a las formas intracelulares que se producen en infecciones in vivo $(20,31)$. En contraste, Lamy informa la transformación de Leishmania a temperaturas bajas, mediante la infección a macrófagos, indicando que la temperatura no es un factor crítico en el proceso de transformación de promastigote a amastigote (3-6). Estos resultados sugieren que la interacción entre el parásito y la célula hospedera o el microambiente generado dentro de la vacuola parasitófora pueden jugar un papel importante en la transformación. Sin embargo, el posible efecto de estas variables en la transformación no ha sido explorado experimentalmente.

Debido a que es posible infectar macrófagos in vitro a temperaturas en las cuales rutinariamente se mantiene la forma extracelular (promastigote), se hace factible evaluar el efecto del aumento de la temperatura en la transformación de promastigote a amastigote de Leishmania durante la interacción con su célula blanco.
El objetivo del presente trabajo fue evaluar si la transformación intracelular de promastigotes en amastigotes ocurre a $24^{\circ} \mathrm{C}$, utilizando criterios de microscopía, ultraestructurales e inmunológicos.

\section{Materiales y métodos}

Parásitos: los parásitos utilizados corresponden a la línea celular de Leishmania amazonensis WR303, mantenida en el Laboratorio de Parasitología del Instituto Nacional de Salud en medio de Schneider, suplementado con $20 \%$ de suero fetal bovino y $20 \mu \mathrm{g} / \mathrm{mL}$ de sulfato de gentamicina. $\mathrm{Su} \mathrm{pH}$ final es 7,4 . Los promasti-gotes en cultivo se mantienen a $24^{\circ} \mathrm{C}$, con una concentración inicial de $1 \times 10^{6}$ parásitos $/ \mathrm{mL}$ y dilución del cultivo en medio completo cada cuatro días.

Macrófagos: se utilizaron células de la línea murina J-774, mantenidas en medio RPMI-1640 suplementado con $10 \%$ de suero fetal bovino y 25 $\mu \mathrm{g} / \mathrm{mL}$ de sulfato de gentamicina. Las células se incubaron a $37^{\circ} \mathrm{C}$ en atmósfera de $5 \%$ de $\mathrm{CO}_{2}$ en monocapas sobre cajas plásticas de $25 \mathrm{~cm}^{2}$.

Infecciones: las infecciones se llevaron a cabo colocando en contacto dos cajas de cultivo de macrófagos ( $80 \%$ de confluencia) en una relación 1:10 con una suspensión de promastigotes de fase estacionaria $(17,18,31)$, e incubando a $24 \mathrm{C}$ en atmósfera de $5 \% \mathrm{CO}_{2}$ durante cuatro horas. Después de este tiempo, los parásitos que no estaban interactuando con los macrófagos se retiraron mediante tres lavados con RPMI. Se adicionó medio RPMl 1640 suplementado con $10 \%$ de suero fetal bovino y las muestras se incubaron a 24 y $33^{\circ} \mathrm{C}$, respectivamente, con el fin de seguir la infección a estas dos temperaturas durante 48 horas.

Microscopía de luz: las muestras se tomaron de cada una de las cajas, en tres momentos diferentes: en el momento del contacto de los parásitos con los macrófagos, 24 y 48 horas después. Las muestras se colorearon con Giemsa. Se recolectaron células infectadas a las dos temperaturas en los tiempos referidos previamente, para incluirse en resina y preparar cortes de 500 $\mu \mathrm{m}$ que se colorearon con azul de toluidina para su observación. 
Inmunofluorescencia: se tomaron muestras de las infecciones a 24 y $33^{\circ} \mathrm{C}$; se lavaron en PBS para retirar el medio de cultivo y se procesaron de acuerdo con Antoine (21), para ser expuestas a reacción con el anticuerpo 2A3-26 donado por J-C Antoine del Instituto Pasteur. Brevemente, las células infectadas se fijaron con paraformaldehído al $4 \%$, se permeabilizaron con saponina $10 \mathrm{mg} /$ $\mathrm{mL}$ en PBS, para ser incubadas por una hora con el anticuerpo primario diluido 1:100 y, después de tres lavados de diez minutos, incubadas por el mismo tiempo con el conjugado antirratónfluoresceína, diluido 1:50.

Microscopía electrónica: se retiraron los cultivos de macrófagos infectados y mantenidos a las dos temperaturas de la caja de cultivo, 24 y 48 horas después de la infección, para ser procesados en suspensión. Cada muestra se fijó durante 12 horas con glutaraldehído al $2,5 \%$ en solución amortiguadora de fosfatos $0,1 \mathrm{M} \mathrm{y} \mathrm{pH}$ de 7,2 . La postfijación se realizó con tetróxido de osmio al $1 \%$ por una hora, se deshidrató completamente con concentraciones crecientes de etanol y se incluyó en resina L-R WHITE, con acelerador de polimerización. Las rejillas se colorearon con acetato de uranilo y citrato de plomo.

\section{Resultados}

Con el propósito de establecer si los macrófagos murinos de la línea J-774 son blanco de la infección por promastigotes de Leishmania amazonensisa $24^{\circ} \mathrm{C}$, se incubaron macrófagos y parásitos en una relación 1:10 durante 4 horas en atmósfera de 5\% de $\mathrm{CO}_{2}$. Después de este tiempo, se retiraron los parásitos no adheridos mediante lavados en medio RPMl y los macrófagos infectados se incubaron a 24 y a $33^{\circ} \mathrm{C}$.

El porcentaje de infección para las dos muestras se cuantificó contabilizando el número de macrófagos infectados con relación al número total de macrófagos. Como se muestra en el cuadro 1 , los parásitos infectan macrófagos mantenidos a temperaturas bajas $\left(24^{\circ} \mathrm{C}\right)$, con un porcentaje de infección similar a macrófagos mantenidos a la temperatura control $\left(33^{\circ} \mathrm{C}\right)$.

Estos resultados confirman la capacidad de promastigotes de Leishmania amazonensis de
Cuadro 1. Porcentaje de macrófagos infectados 24 y 48 horas postinfección.

\begin{tabular}{|c|c|c|c|c|}
\hline \multirow[t]{2}{*}{$T$} & \multicolumn{2}{|c|}{$\begin{array}{c}\% \text { macrófagos } \\
\text { infectados }\end{array}$} & \multicolumn{2}{|c|}{$\begin{array}{l}\text { Promedio } \\
\text { amastigote/cel }\end{array}$} \\
\hline & $24 \mathrm{~h}$ & $48 \mathrm{~h}$ & $24 \mathrm{~h}$ & $48 \mathrm{~h}$ \\
\hline $24^{\circ} \mathrm{C}$ & $52,5(9,3)$ & $28,5(8,5)$ & $2,5(0,5)$ & $1,8(0,59)$ \\
\hline $33^{\circ} \mathrm{C}$ & $64,2(12,6)$ & $42,5(17)$ & $3,05(0,85)$ & $2,0(0,4)$ \\
\hline
\end{tabular}

infectar macrófagos murinos de la línea J-774, a $24^{\circ} \mathrm{C}$ en la cual la transformación de promastigote a amastigote no se produce en sistemas axénicos.

Con el objeto de estudiar si las infecciones a $24^{\circ} \mathrm{C}$ conducen a la transformación de promastigotes de Leishmania amazonensis en la forma intracelular (amastigote), se realizó una comparación, mediante microscopía de luz, de los parásitos intracelulares observados a $24^{\circ} \mathrm{C}$ y a $33^{\circ} \mathrm{C}$.

En la figura 1, se muestran macrófagos infectados provenientes de infecciones tanto a 24 como a $33^{\circ} \mathrm{C}$, fijados en metanol y, posteriormente, teñidos con Giemsa. En las dos preparaciones, se pueden apreciar formas aflageladas del parásito y elipsoides al interior de vacuolas citoplasmáticas de los macrófagos.

Con el propósito de evidenciar si los parásitos intracelulares de infecciones a $24^{\circ} \mathrm{C}$ son amastigotes, se utilizó el anticuerpo monoclonal 2A326 que reconoce antígenos específicos de la forma amastigote (21). El anticuerpo se incubó con macrófagos parasitados a cada una de las dos temperaturas y la reacción se visualizó mediante el uso de un anticuerpo contra inmunoglobulina de ratón, conjugado con fluoresceína. Observaciones bajo microscopía de fluorescencia demuestran que los parásitos intracelulares en macrófagos mantenidos a $33^{\circ} \mathrm{C}$ presentan un patrón de reacción intenso sobre la superficie celular, con regiones de mayor intensidad y una posible localización cortical (figura 2). Estos resultados concuerdan con las observaciones previamente informados por Antoine (21). Cuando se observaron macrófagos infectados a $24^{\circ} \mathrm{C}$ bajo microscopía de fluoresecencia, los parásitos intracelulares mantenidos carecían de señal fluorescente. Estos resultados demuestran que 

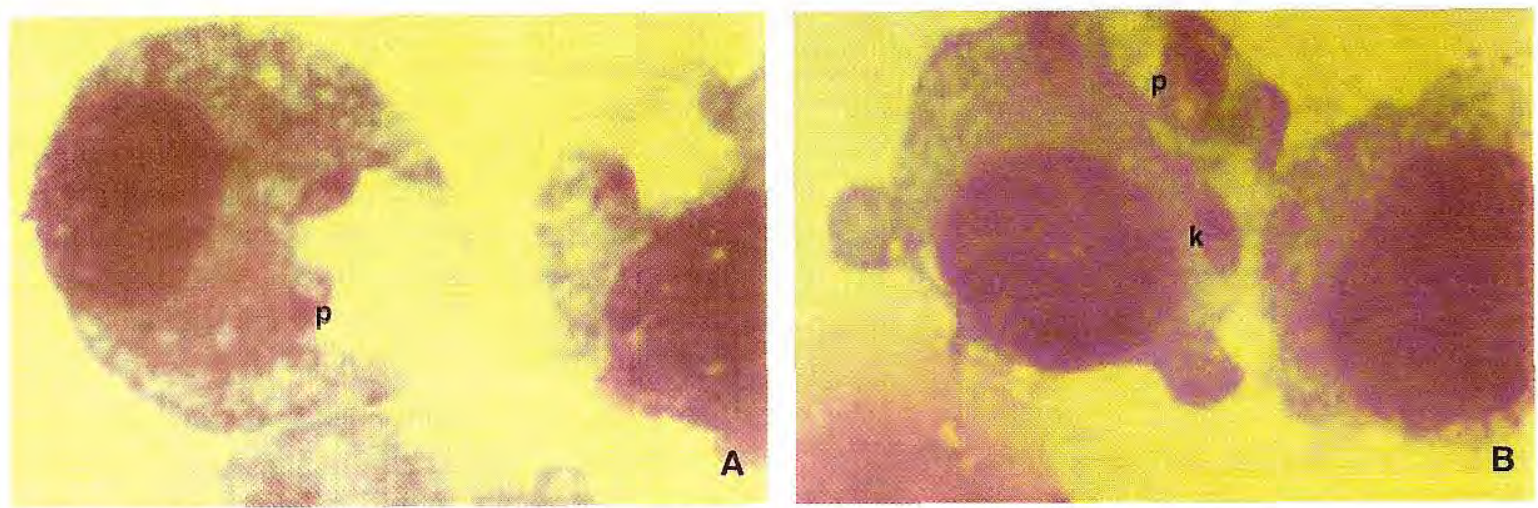

Figura 1. Macrófagos infectados con Leishmania. Coloración de Giemsa: A) macrófago infectado a $33^{\circ} \mathrm{C}(100 \mathrm{X})$; $\left.\mathrm{B}\right)$ macrófago infectado $24^{\circ} \mathrm{C}(100 \mathrm{X})$. Se muestran parásitos intracelulares $(\mathrm{P})$ con cinetoplastos visibles $(\mathrm{K})$.
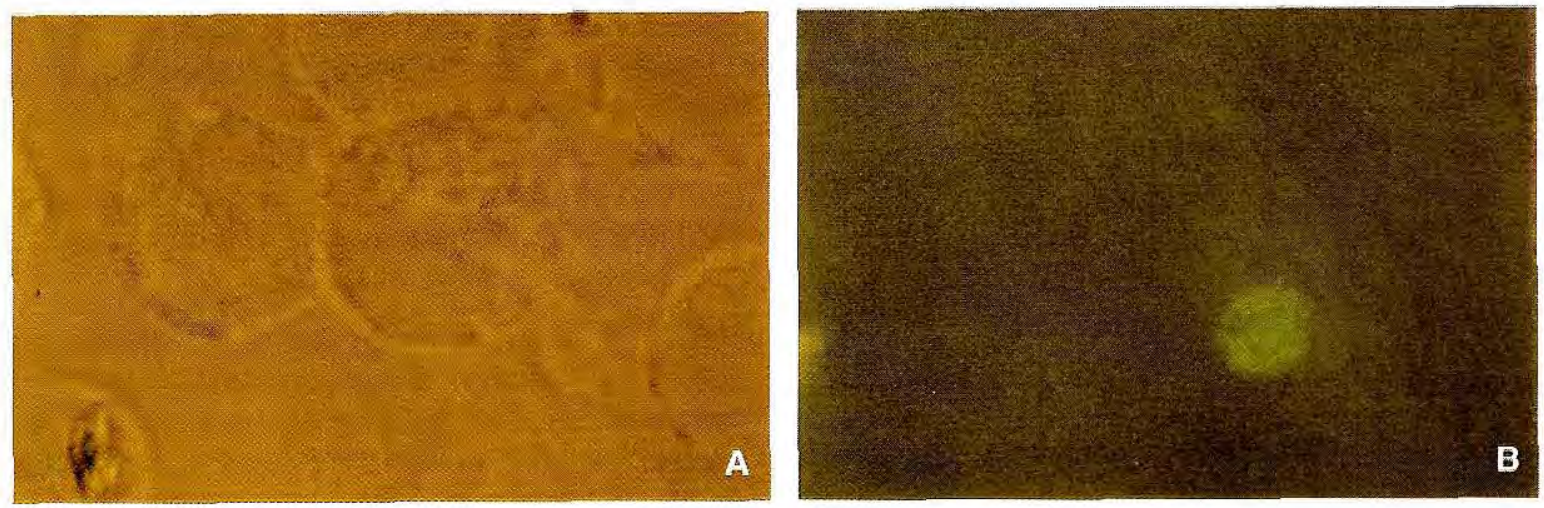

Figura 2. Inmunofluorescencia indirecta de macrófagos infectados a $33^{\circ} \mathrm{C}$ utilizando el anticuerpo monoclonal 2A3-26. A) Microscopía de luz de un macrófago infectado mostrando un parásito intracelular (flecha); B) Nótese la reacción positiva, evidenciada por fuerte fluorescencia sobre el citoplasma del parásito.

los parásitos que infectan macrófagos a $24^{\circ} \mathrm{C}$, no expresan algunos antígenos presentes en parásitos que infectan macrófagos a temperaturas mayores.

Dado que los resultados obtenidos por microscopía de fluorescencia indican que los parásitos intracelulares a $24^{\circ} \mathrm{C}$ presentan diferencias con respecto al control, se decidió utilizar otros criterios de comparación de las formas intracelulares.

La observación por microscopía de luz de cortes semifinos $(500 \mu \mathrm{m})$ de cada una de las muestras, se realizó porque permite obtener una mayor resolución morfológica y, por tanto, una mejor caracterización de los parásitos intracelulares. Las imágenes de muestras fijadas e incluidas en resina hidrosoluble fueron obtenidas de cortes de ésta y coloreadas con azul de toluidina. Como se puede observar en la figura 3, los parásitos intracelulares están incluidos en vacuolas citoplasmáticas derivadas del macrófago, con un predominio de formas alargadas en forma de huso en las muestras mantenidas a $24^{\circ} \mathrm{C}$ y de formas elipsoides y redondeadas en las células mantenidas a $33^{\circ} \mathrm{C}$.

Con el objeto de confirmar los resultados descritos anteriormente, se procesaron muestras para microscopía electrónica de transmisión. En estas imágenes, los macrófagos mantenidos a $33^{\circ} \mathrm{C}$ muestran parásitos intracelulares con las características morfológicas descritas previamente en la literatura para amastigotes de Leishmania amazonensis $(13,22)$, tales como: un flagelo retraido al interior de una bolsa flagelar dilatada, cercano a vesículas rodeadas de membrana conformando el polo flagelar, núcleo y cinetoplasto 

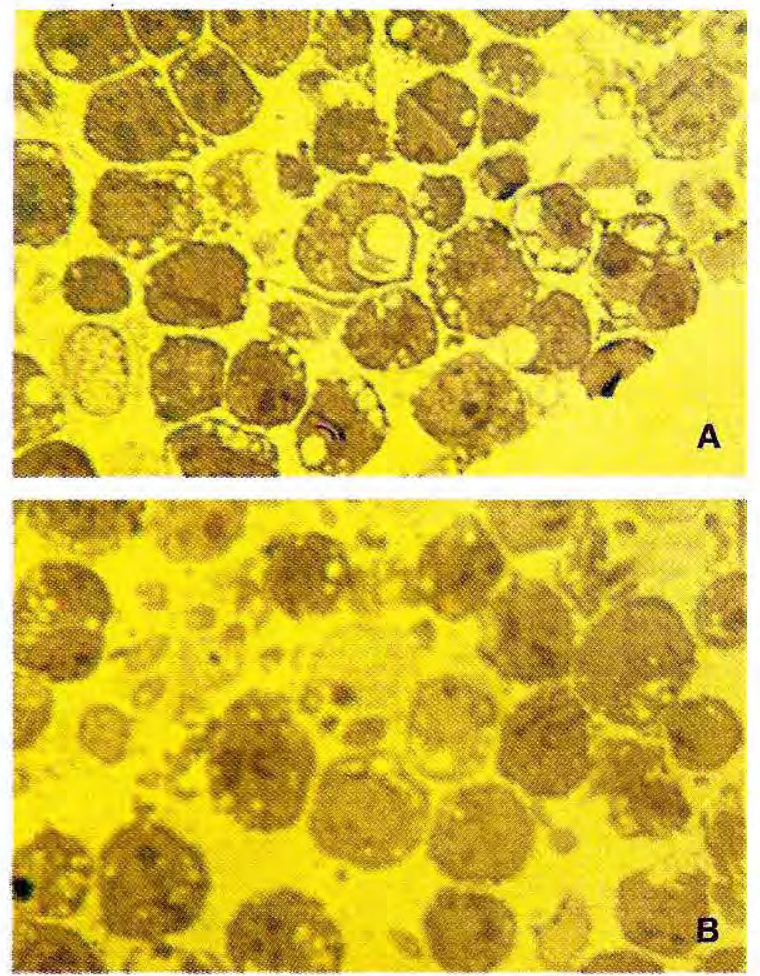

Figura 3. Cortes semifinos coloreados con azul de toluidina de macrófagos infectados. A) Macrófago infectado a $24^{\circ} \mathrm{C}$ (100X); B) Macrófago infectado a $33^{\circ} \mathrm{C}(100 \mathrm{X})$. En ambos casos, obsérvense los parásitos intracelulares $(\mathrm{P})$ al interior de una vacuola parasitófora.

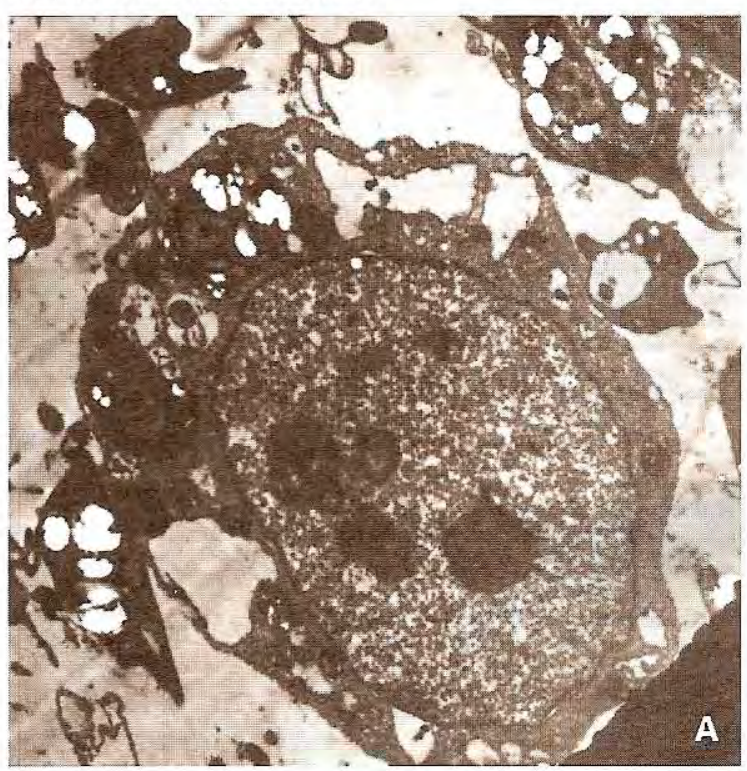

(figura 4). Las imágenes de los macrófagos mantenidos a $24^{\circ} \mathrm{C}$ muestran parásitos incluidos en vacuolas que presentan núcleo y cinetoplasto visible y contenido citoplasmático difuso (figura $5 A$ ). En otras imágenes a esta misma temperatura, se observan parásitos intracelulares flagelados, con forma de huso y en los cuales no se aprecian claramente las características propias de amastigotes (figura 5B).

Estos resultados ponen en clara evidencia las diferencias ultraestructurales entre los parásitos intracelulares mantenidos a 24 y a $33^{\circ} \mathrm{C}$.

\section{Discusión}

En el presente estudio se llevaron a cabo infecciones de la línea de macrófagos murinos J774 con promastigotes de Leishmania amazonensis a diferentes temperaturas, con el objeto de evaluar la influencia de esta variable en el proceso de transformación de promastigote a amastigote durante la interacción con la célula hospedera.

Mediante diferentes técnicas se evaluaron los cambios sufridos por el parásito intracelular a cada temperatura. Los parásitos intracelulares en macrófagos mantenidos a 33 y a $24^{\circ} \mathrm{C}$ son células

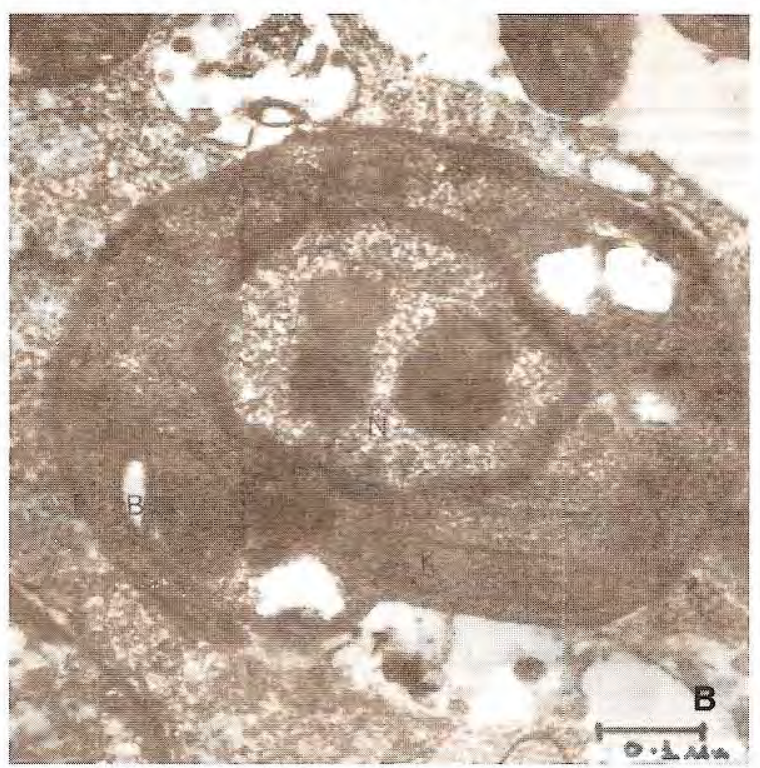

Figura 4. Microscopía electrónica de transmisión de macrófagos infectados a $33^{\circ} \mathrm{C}$. A) Macrófago infectado a $33^{\circ} \mathrm{C}(6.600$ $\mathrm{X})$, que muestra un parásito intracelular $(\mathrm{P})$; B) Amastigote intracelular a $33^{\circ} \mathrm{C}(39.000 \mathrm{X})$. Ampliación del parásito de la fotografía anterior, mostrando el flagelo $(F)$ retraido en bolsa flagelar $(B)$, núcleo $(N)$, cinetoplasto $(K)$. 

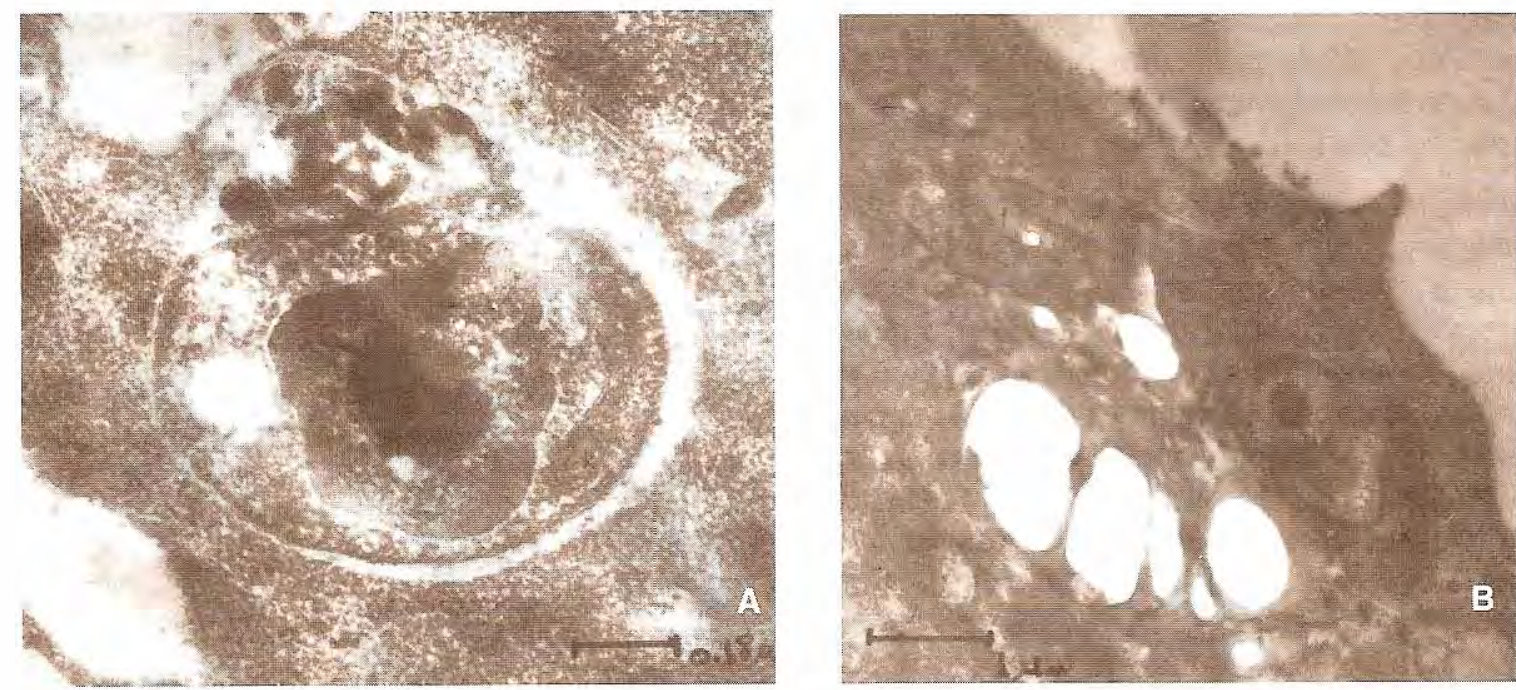

Figura 5. Microscopía electrónica de transmisión de macrófagos infectados a $24^{\circ} \mathrm{C}$. A) Parásitos intracelulares, núcleo y cinetoplasto $(\mathrm{K})$ visibles $(52.000 \mathrm{X})$; B) Parásito intracelular, mostrando flagelo visible $(\mathrm{F})$, núcleo $(\mathrm{N})$, cinetoplasto $(\mathrm{K})$ $(18.000 \mathrm{X})$.

aflageladas que presentan una forma redondeada según se observó en las coloraciones con Giemsa (figura 1). En contraste, los cortes semifinos coloreados con azul de toluidina, muestran que los parásitos intracelulares mantenidos a $33^{\circ} \mathrm{C}$ son aflagelados y presentan una morfología redondeada, a diferencia de los parásitos incubados a $24^{\circ} \mathrm{C}$ que se observan alargados y de mayor tamaño (figura 3).

Las reacciones de los parásitos intracelulares mantenidos a $33^{\circ} \mathrm{C}$ con el anticuerpo monocional, 2A3-26 específico de amastigotes (21) son positivas por inmunofluorescencia (figura 2) y negativas por el mismo método con los parásitos de infecciones a $24^{\circ} \mathrm{C}$. A su vez, la ultraestructura de los parásitos intracelulares mantenidos a $33^{\circ} \mathrm{C}$ muestra un contorno celular redondeado, núcleo y cinetoplasto, una bolsa flagelar distendida, el flagelo se ve retraido en el polo anterior de la célula y vecino a una estructura delimitada por una membrana electrodensa (figura 4). Las observaciones ultraestructurales realizadas con los parásitos provenientes de infecciones a $24^{\circ} \mathrm{C}$ son diferentes. En éstos, se observan predominantemente células flageladas alargadas con núcleo y cinetoplasto (figura 5).

De lo anterior se puede concluir que los parásitos intracelulares producto de infecciones de promastigotes de Leishmania amazonensis a macrófagos murinos $\mathrm{J}-774$, a $33^{\circ} \mathrm{C}$ son diferentes antigénica, morfológica y ultraestructuraimente de los parásitos intracelulares obtenidos a $24^{\circ} \mathrm{C}$. Teniendo en cuenta que las características ultraestructurales y antigénicas observadas en los parásitos a $33^{\circ} \mathrm{C}$ corresponden a las descritas en la literatura $(13,21,22)$ para la forma amastigote del parásito, se concluye que las infecciones a macrófagos murinos $\mathrm{J}-774$ por parte de promastigotes de Leishmania amazonensis, a $24^{\circ} \mathrm{C}$ no conduce a su transformación en amastigotes.

Los resultados presentados en este estudio están en contradicción con los obtenidos por el grupo de Lamy (3-6), en donde se plantea que la temperatura no es un factor indispensable en el proceso de transformación de promastigote a amastigote en Leishmania. Una posible explicación es que el diseño experimental difiera entre los dos estudios. Por ejemplo, las infecciones, en los estudios de Lamy se llevaron a cabo con cultivos primarios de macrófagos murinos y con promastigotes de Leishmania donovani. Bajo estas condiciones, los resultados no son estrictamente comparables con los obtenidos en el presente estudio. Otra explicación es que las herramientas de evaluación en los 
estudios informados previamente y las del presente trabajo son diferentes; Lamy y colaboradores evaluaron la transformación únicamente mediante microscopía de luz.

El hecho de que a $24^{\circ} \mathrm{C}$ los parásitos observados no correspondan ultraestructural y antigénicamente a amastigotes, tendría dos diferentes interpretaciones: 1) que el aumento en la temperatura es esencial para la transformación del promastigote en la forma de amastigote, lo que permite al parásito sobrevivir dentro de la vacuola parasitófora; 2) que el macrófago se encuentre en condiciones ambientales $\left(24^{\circ} \mathrm{C}\right)$ donde sus funciones celulares no se realizan de una manera adecuada y el promastigote intracelular no recibe las señales apropiadas para su transformación. Por ejemplo, es probable que a esta temperatura la fluidez de las membranas de la célula hospedera se encuentre alterada y no se lleve a cabo fusión de la vacuola parasitófora con las vesículas lisosómicas, lo cual podría ser importante para que el promastigote fagocitado se transforme en un amastigote viable.

Aun cuando los resultados arrojados por este estudio son consistentes con la hipótesis de que la temperatura es una variable necesaria en el proceso de transformación de promastigote a amastigote de Leishmania amazonensis, no se puede concluir definitivamente que la temperatura es una variable suficiente en este proceso, ya que los ensayos de transformación en modelos axénicos mediante cambio en la temperatura, producen células similares a amastigotes, pero no reunen todas las características de éstos (2426), y es solamente cuando se introducen otras variables, como $\mathrm{pH}$, que se obtienen mejores resultados en la transformación $(7,13,19,26)$.

Finalmente, se ha informado que los cambios morfológicos (de tripomastigote a amastigote) (28) en tripomastigotes de Trypanosoma cruzi -otro género de la familia Trypanosomatidae- se producen al interactuar in vitro con fragmentos de fibronectina. Estas asociaciones permiten postular que la interacción del parásito con la célula hospedera es un factor importante en la transformación de formas flageladas en aflageladas $(29,30)$.
En conclusión, es necesario considerar el papel de la temperatura en la transformación de promastigote en amastigote de Leishmania de manera más relativa y explorar nuevas variables.

\section{Agradecimientos}

Los autores le agradecen a Jorge Contreras quien realizó las primeras observaciones de infección de Leishmania mexicana a macrófagos $\mathrm{J}-774$ a $24^{\circ} \mathrm{C}$ e inspiró la realización de este estudio. Así como a Ladys Sarmiento del Grupo de Patología del INS quien colaboró en la microscopía electrónica.

\section{Referencias}

1. Antonie JC, Prinac E, Jouanne C, Bongrand P. Parasitophorus vacuoles of Leishmania amazonensis infected macrophages maintain acid $\mathrm{pH}$. Infect Immun 1990;58:779-787.

2. Molyneux DH, Killick-Kendrick R. Morphology, ultraestructure and life cycle. In: Peters W, KillickKendick R. The leishmaniases in biology and medicine. Vol I. London: Academic Press; 1987.

3. Lamy LW, T Lamy-RouxI L,1967. Influence de la tempèrature sur la formation réciproque des formes flagellées et aflagellées de Leishmania en présence de macrophages peritoné aux de Souris in vitro. Paris: C.R. Acad. Sc. t264, Avril serie D 1889-1991.

4. Lamy L. Cycle biologique complet de Leishmania invi tretélute de diver comportements. Prostistologica 1967;3:359-63.

5. Lamy L. Transformation intracellulaire des formes amastigotes de Leishmania donovani ét Trypanosoma cruzi en formes mastigotes. Prostistologica T.VI, Fasc.1970;457-66.

6. Lamy I. La transformation réciproque des formes mastigotes et amastigotes de Leishmania et son déterminisme en présence de cellules vivants in vitro. Ann Ins Pasteur 1969;7:545-55.

7. Pan A. Leishmania mexicana: serial cultivation of intracellular states in a cell-free medium. Exp Parasitol 1984:58:72-80.

8. Shapiro M, McEwen JM, Jaffe CL. Temperature effects on molecular processes lead to state differentation in Leishmania. The EMBO J 1988;7:2895-901.

9. Van der Ploeg L, Giannini S, Cantor C. Heat shock genes: regulatory role for differentiation in parasitic protozoa. Science 1985;228:1443-6. 
10. Hunter JR, Cook CL, Hensen SA. Temperature induced in vitro transformation of Leishmania mexicana. Acta Tropica 1982;39:143-50.

11. Zilberstein D, Blumenfeld $\mathbf{N}$, Liveanu V, Gepstein A, Jaffe C. Growth at acidic pH induces an amastigote stage-specific protein in Leishmania promastigotes. Mol Biochem Parasitol 1991;45:175-8.

12. Bates PA, Robertson CD, Tetley T, Coombs GH. Axenic cultivation and characterization of Leish-mania mexicana amastigote-like forms. Parasitology 1992;105:193-202.

13. Pan A, Monroe D, Eperon S, Rivas L, Hodgkinson V, et al. Developmental life cycle of Leishmania cultivation and characterization of culture extracellular amastigotes. J Euk Microbiol 1993;40:213-23.

14. Bates PA. Complete developmental cycle of Leishmania mexicana in axenic culture. Parasitology 1994;108:1-9.

15. Bates PA. Axenic culture of Leishmania amastigotes. Parasitology Today 1993;9:143-6.

16. Al-Bashir NT, Rassan MB. Axenic cultivation of amastigotes of Leishmania donovani and Leishmania major and their infectivity. Ann Trop Med Parasitol 1992;86:487-502.

17. Chang KP, Dwyer DM. Leishmania donovani. Hamster macrophage interaction in vitro: cell entry, intracellular survival and multiplication of amastigotes. J Exp Med 1978;147:515-30.

18. Chang KP, Dwyer DM. Multiplication of human parasites Leishmania donovani in phagolysosomas of hamster macrophages in vitro. Science 1981; 193:678-80.

19. Zilberstein $\mathbf{D}$, Shapiro $\mathbf{M}$. The role of $\mathrm{pH}$ and temperature in the development of Leishmania parasites. Annu Rev Microbiol 1994;48:449-70.

20. Hart DT, Vikerman K, Coombs GH. A quick simple method for purifying Leishmania mexicana amastigotes in large numbers. Parasitology 1981;82:345-55.
21. Lang T, Chastellier C, Frehel C, Hellio R, Metezeau P, de Souza B. Distribution of MHC class I and of MHC class II molecules in macrophages infected with Leishmania amazonensis, J-Cell. Science 1994;107:69-82.

22. Pan A, Pan S. Leishmania mexicana: comparative fine structure of amastigotes and promastigotes in vitro and in vivo. Exp Parasitol 1986;62:254-65.

23. Jaffe C, Rachamin N. Amastigote state-specific monoclonal antibodies against Leishmania major Infect Immun 1989;57:3770-7.

24. Eperon S, McMahon-Pratt D. Extracellular amastigote-like form of Leishmania panamensisand L. braziliensis. II.Stage- and species-specific monoclonal antibodies. J Protozool 1989;36:510-8.

25. Rainey P, Spithill T, McMahon-Pratt D, Pan A. Biochemical and molecular characterization of Leishmania pifanoi amastigotes in continous axenic culture. Mol Biochem Parasitol 1991;49:111-8.

26. Eperon S, McMahon-Pratt D. Extracellular cultivation and morphological characterization of amastigote-like forms of Leishmania panamensis and L. braziliensis. Int J Protozool 1989;36:502-10.

27. Kahl L, McMahon-Pratt D. Structural and antigenic charaterization of a species- and promastigotespecific Leishmania mexicana amazonensis membrane protein. J Immunol 1987; 138:1587-95.

28. Ouassi A, Cornette J, Schoeneck R, PlumasMarty B, Taibi A, et al. Fibronectin cleavage fragments provide a growth factor-like activity for differentiation of Trypanosoma cruzi trypomastigotes to amastigotes. Eur J Cell Biology 1992.

29. Livingston B, Wilt F. Cell interaction in invetebrate development. Current Opinion in Cell Biology 1993;5:839-43.

30. Clark E, Brugge J. Integrins and signal transduction pathways: the road taken. Science 1995;268:2339.

31. Chang KP. Human cutaneous Leishmania in a mouse macrophage line: propagation and isolation of intracellular parasites. Science 1980;209:1240-2. 